NASA Technical Memorandum 107319

97732

\title{
Status of Electrical Actuator Applications
}

Mary Ellen Roth and Linda M. Taylor

Lewis Research Center

Cleveland, Ohio

Irving G. Hansen

Motive Power Development

San Diego, California

Prepared for the

31st Intersociety Energy Conversion Engineering Conference cosponsored by IEEE, AIChE, ANS, SAE, AIAA, and ASME Washington, D.C., August 11-16, 1996

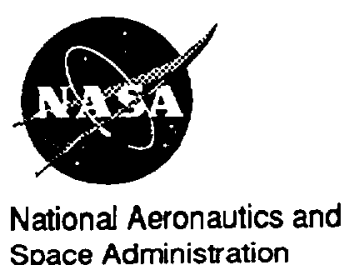

Space Administration 


\title{
STATUS OF ELECTRICAL ACTUATOR APPLICATIONS
}

\author{
Mary Ellen Roth \\ Linda M. Taylor \\ NASA Lewis Research Center \\ 21000 Brookpark Road \\ Cleveland, Ohio 44135 \\ Phone: (216) 433-8061, 8478 \\ Fax: (216) 433-2469 \\ Irving G. Hansen \\ Motive Power Development \\ 7905 Silverton Ave., Suite 109 \\ San Diego, California, 92126 \\ Phone: (619) 536-5555
}

Fax: (619) $536-5558$

\begin{abstract}
An ever increasing number of actuation functions historically performed by hydraulics or pneumatics are being accomplished by electric actuation. If "end to end" systems are considered, electric actuators (EA's) are potentially lighter and more efficient. In general, system redundancies may be more easily implemented and operationally monitored. Typically, electrical components exhibit longer mean times to failure and projected lifetime costs of EA's are potentially much lower than those of other options.

EA's have certain characteristics which must be considered in their application. The actual mechanical loadings must be established, for the more easily controlled EA may be operated much closer to its full capabilities. At higher rates of motion, EA's are operating as constant power devices. Therefore, it may be possible to start a movement that can not be stopped. The incorporation of high power electronics into remote locations introduces new concerns of EMI and thermal control. It is the management of these and other characteristics that forms the engineering design challenges.

Work is currently in progress on EA's for aircraft and expendable launch vehicies. These applications span from ten to $40+$ horsepower. The systematics and status of these actuators will be reported along with current technical trends in this area.
\end{abstract}

\section{INTRODUCTION}

An ever increasing number of actuation functions historically performed by hydraulics or pneumatics are being accomplished by electric actuation. If "end to end" systems are considered, electric actuator (EA) systems offer lighter weight, increased reliability, maintainability and operability.
Current NASA EA programs address both launch vehicle and aircraft EA applications. The objective of the Evolutionary Launch Vehicle (ELV) Electrical Actuation (ELA) System Modernization Program is to demonstrate a redundant EA system with advanced avionics and upgraded power source. The NASA Power By Wire (PBW) program, subelement to the Advanced Subsonic Transport Fly By Light/PBW program, is a multi-year program to design an all-electric secondary power system for a 300 passenger-class commercial aircraft. Under this program several redundant EAs will be demonstrated in the PBW Power Management and Distribution Test Bed. An EHA for an aileron surface will also be flight tested.

There are two basic types of EAs: electromechanical and electrohydraulic. This paper will only address electromechanical actuators because all previous and most current EA programs at NASA LeRC have been EMA developments. The advantages of EA systems over conventional systems will be discussed. The systematics and status of the actuators will be reported along with current technical trends in this area.

\section{WHY SELECT ELECTRICAL ACTUATION}

Conventional centralized hydraulic systems used in today's launch vehicles perform well but are an operational nightmare. The cost to maintain and operate these systems is prohibitive and contributes to today's excessive launch costs. In a study conducted by NASA-Kennedy Space Center (McCleskey and Rushing, 1992), it was shown that a cost savings of $\$ 3 \mathrm{M}$ per flight could be realized by replacing the hydraulic-powered Solid Rocket Booster Thrust Vector Control (TVC) actuator system with an electric one. Studies on other vehicles have shown similar savings and operational advantages to replacing 
hydraulics with EA systems. These advantages include: increased reliability, improved safety through the elimination of high pressure and hazardous fluids, reduction in check-out time and increased ability to launch on demand.

Likewise, studies on commercial aircraft for NASA's Power by Wire program have shown significant benefits to replacing the pneumatic and hydraulic systems with an all electric secondary power system, including EAs for the control surfaces (Murray, 1992 and Renz, 1992). An all electric secondary power system will weigh less than the hybrid system, resulting in reduced fuel consumption, which leads to lower operating cost, extended range or increased cargo capacity.

\section{EA TECHNICAL TRENDS}

Intensive work in the area of electric actuators has been ongoing at NASA LeRC since the mid-1980's. Induction motor drives starting at the $5 \mathrm{Hp}$ level and building up to $70 \mathrm{Hp}$ flight-type packaged drives have been demonstrated. EA subsystems have been tested up to $30 \mathrm{Hp}$. Advanced induction motors, with peak power densities approaching $3.5 \mathrm{Hp}$ per pound have been achieved. LeRC has concentrated its efforts in the areas of soft switched converter designs and Indirect Field Oriented Control (IFOC) induction motor drives. This section will discuss the LeRC approach to EA system design and redundancy management.

\section{Motor Selection}

All electric motors are $A C$ motors in the sense that current must be interrupted and a magnetic field reversed in order to allow full rotation. Furthermore, all electric motors are bidirectional in the sense that an overhauling load which tends to drive the motor will cause the motor to generate and return energy back onto the buss, as shown in Figures 1 and 2.

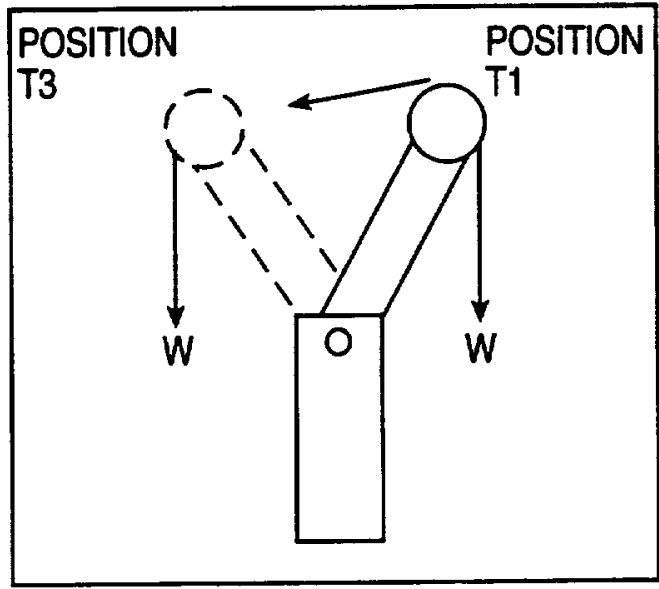

FIGURE 1: OVER HAULING LOAD
This bidirectionality becomes very important when more than one motor is connected to a dynamic load. Torque summing of small motors is attractive in regards to inertia and redundancy, but avoiding force fights between synchronous bidirectional motors is difficult at best. Torque fight problems are shared with other synchronous machines such as the switched reluctance motor. The switched reluctance motor has other undesirable characteristics such as acoustic noise, torque ripple and control complexity that limits its application to actuators. Torque fight is considerably reduced when induction motors are used as their output torque reduces to zero at synchronous speed. This attribute, along with their comparable power density, robust construction and high temperature operation, makes the IM the preferred choice for many, although not all, EA applications.

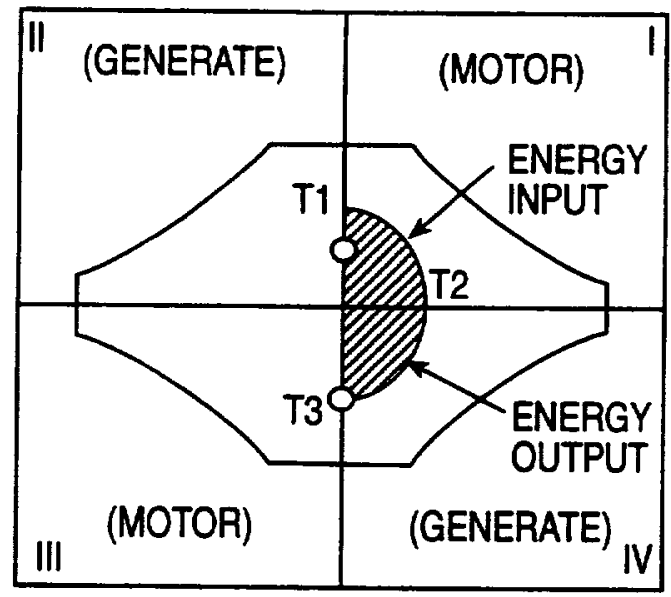

FIGURE 2: FOUR QUADRANT OPERATION

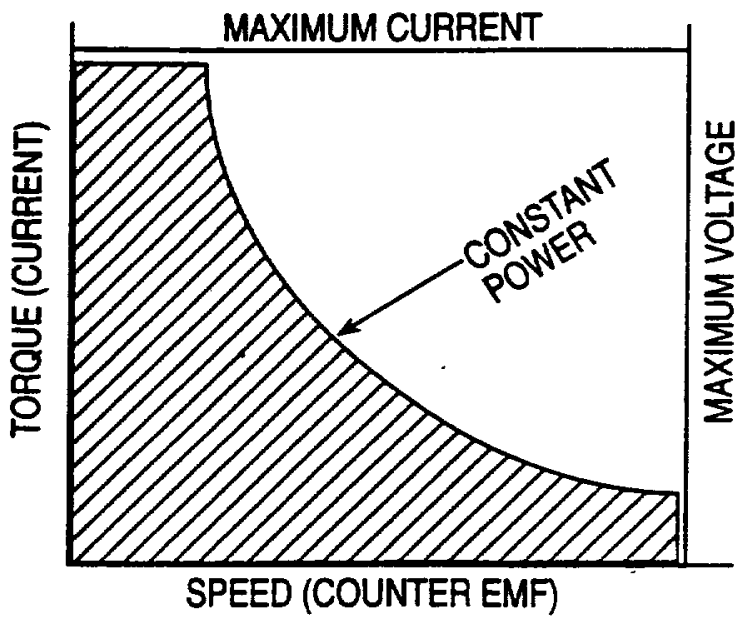

FIGURE 3: CONSTANT POWER OPERATION

\section{Power Processor Topologies}

In any actuator application, the maximum available voltage and current is limited by either the source or the ratings of the 
power electronics, as shown in Figure 3. Peak torque is limited by the available current until a point is reached where the counter-emf begins to reduce the current, thus, initiating constant power operation. In this region of operation all the mechanical loadings, static and dynamic, must not exceed the peak power capabilities. The control of dynamic loads requires that the inertial effects of both the load and motor/actuator be considered.

LeRC has concentrated its power electronics efforts on softswitched resonant converter topologies and the pulse population modulation technique for waveform synthesis. The power available to the EA is limited, and therefore, the most efficient converter is desirable. Soft-switched designs result in overall lower loss by eliminating essentially all switching losses. EMI is also reduced as compared to hard switched converters.

\section{Power sources}

The power source for the typical launch vehicle EA must have high power density and be capable of handling high current discharge and charge (for reverse energy pulses). Safety and ease of handling are also desirable attributes. Silver Zinc $(\mathrm{AgZn})$ batteries are one possible candidate. A more promising scenario is the use of a battery-super capacitor combination source. The super-cap would provide the peak power demands of the EA and the battery would handle the steady state power demand. Preliminary tests conducted at the MSFC using a AgZn-Super capacitor combination has shown promising results. Performance requirements can be met and a significant reduction in the total power source weight can be achieved (Hall and Merryman, 1995). Other options include the use of a flywheel instead of a super capacitor to supply the peak power demands.

On aircraft, and possibly launch vehicles with many EAs for TVC, control surfaces and engine valves, the EAs would be powered from the main power buss. Possible candidates are three phase, constant frequency or high voltage DC converted from the three phase, wild frequency output of an enginemounted generator, high voltage DC or single phase high frequency.

\section{EA SYSTEM ISSUES}

EA's have certain characteristics which must be considered in their application. For example, the more easily controlled EA may be operated much closer to its full capability than an hydraulic actuator. At higher rates of motion, EA's are operating as constant power devices and it may be possible to start a movement that can not be stopped. There can be a considerable amount of dynamic energy stored in the system which can be put back on the power buss during certain movements. The incorporation of high power electronics into remote locations introduces new concerns of EMI and thermal control. The fail safe operational requirements of many actuation systems leads to unique redundancy issues for EAs. It is the management of the different characteristics of EA's that forms the engineering design challenges. A few of these issues will be discussed in more detail in this section.

\section{EMI/EMC Issues}

A consideration in the application of electric actuation is the coupling between the motor windings and the frame of the motor which is typically connected to vehicle structure resulting in the creation of common mode currents. The EMI/EMC standards do not fully recognize common mode currents or define comprehensive testing techniques. However, there are techniques available to control common mode effects, such as common mode chokes, which should be factored into the design as early as possible.

\section{Redundancy}

Redundancy and status management of electric actuators are made difficult by the needs of rapid implementation and fail safe operation. One common approach involves the monitoring of motors and their comparison with a virtual motor residing in software. The sophistication of the model can vary from a simple 'sanity check' to an elaborate failure diagnosis with complexities and response times increasing accordingly.

In order to meet fail safe requirements, multi-channel EA systems are often suggested. Redundant motors, two to four, depending on the level of fault tolerance required, are either torque summed or speed summed. In the case of the torquesummed configuration, if failures are to be accommodated by deenergizing the induction motor, its inertia will remain as a "small" load to the remaining motor(s). If the motor is of the PM type, its field can not be deenergized and therefore, can become a substantial opposing load on the remaining motor(s). In the case of speed-summed PM motors, this problem is avoided, but now the total system weight increases due to the differential gears necessary for speed-summing. Although force fights are possible with IMs, they are less severe and can be avoided altogether through the implementation of synchronous power-sharing software algorithms. System trades need to be completed regarding these issues, before one motor can be chosen over another for a given application. On-going EA demonstration programs, described in detail later in this paper, will be able to resolve at least some of these redundancy issues.

Jamming of the Screw Mechanism. One major concern regarding EA's is the threat of a jam of the screw and how to handle such a failure. Although there is data to suggest that a ballscrew jam is unlikely, in truth all mechanical systems ultimately have single point failure modes. One approach is to implement functional redundancy. For example, several independent control surfaces to perform one function. Another approach would be to develop jam-proof designs for the screw-nut mechanism, such as multiple return paths for the recirculating balls. 
Active-Active vs Active-Standby Systems. Another unresolved redundancy issue is the selection of either ActiveActive(A-A) or Active-Standby(A-S) system operation where more than one motor and electronic unit are available to drive the actuator. In the A-A system, both motor/electronic channels control the actuator. For the A-S system, only one channel operates at a time while the other is in the "standby" mode. In the event of a failure, the standby channel would assume control of the actuator. In the case of the A-A system, the electronic units and motors are operating at half their rated power. For A-S system, only one channel operates at full power. There is a question as to which configuration would result in a lower system failure rate. Early indications are that the A-A would have the lower failure rate. One NASA sponsered study recommends the selection of A-A operation due to lower motor and electronic stresses and reduced operating temperatures since the load is shared between the channels. Also, in the event of a failure, the transition from two channel operation to one channel would be more fluid, as compared to switching from an active to an inactive (standby) channel.

This is due to both sets of electronics and both motors operating at half-power temperatures, thus reducing thermal shock. The disadvantage of the A-A system is that the load must be shared equally between the channels to prevent the possibilty of a torque fight between the two motors. This can be accomplished through more complex software algorithms. On-going NASA programs continue to look at this trade.

\section{Reverse Energy (Generator Mode)}

The torque developed in an electric motor is a function of the magnetic flux density and the area of the air gap. Saturation of the magnetic path limits the developed magnetic shear to 5 to $10 \mathrm{psi}$. For a given size machine, the power may only be increased by increasing the rotor speed. Therefore, to minimize weight, EMAs are typically comprised of high speed motors with gear reductions. As a consequence of the high rotational speed of the rotor, considerable dynamic energy is stored in the rotor and ultimately retumed back into the power system when the motor decelerates. The power system must be capable of accepting high surges of reverse energy, otherwise, a sizable dump resistor must be available to absorb the return energy.

\section{STATUS OF EA PROGRAMS}

Previous NASA LeRC EA programs have addressed only single string systems and neglected the power source. NASA LeRC now has three programs underway that for the first time will address the end to end system design, redundancy management and fault tolerance. One program is for a launch vehicle TVC application. The other two address EAs for commercial aircraft. This section will discuss past program successes and will provide status of on-going EA programs within NASA LeRC.

\section{Completed EA Programs}

Under the Advanced Launch System program and the ELA Technology Bridging program, NASA LeRC and its contractors developed and demonstrated two different types of EA subsystems. A $30 \mathrm{kw} \mathrm{AC}$ resonant link drive was built and tested with both a motor and motor-actuator load (Fulmer, 1993). Problems with the stability of the inverter power source limited testing of the motor driver to $10 \mathrm{Hp}$, $70 \mathrm{~A} \mathrm{~ms} / \mathrm{phase}$. Steady state motor testing on a dynamometer demonstrated converter efficiencies of $95 \%$ at $10 \mathrm{hp}$. EA system tests on the MSFC Inertial Test stand demonstrated a frequency response of $3.2 \mathrm{~Hz}$ at $+/-0.1^{\prime \prime}$.

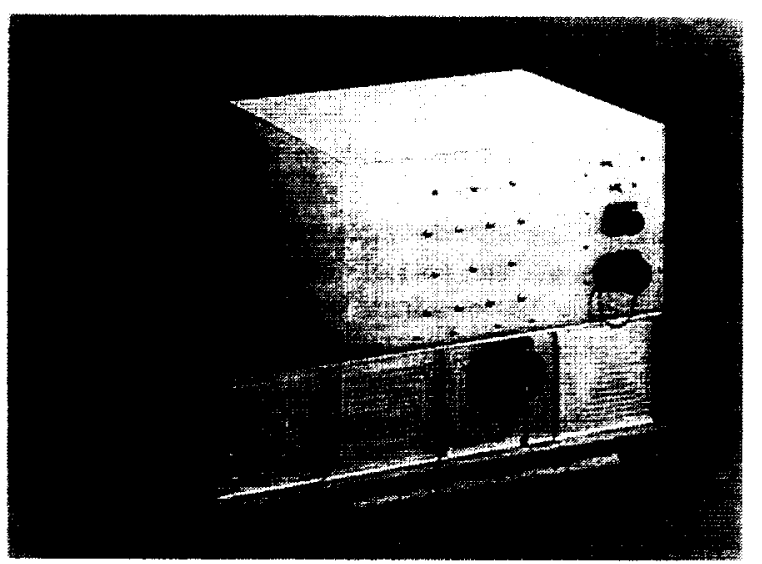

FIGURE 4: AC RESONANT LINK POWER PROCESSOR

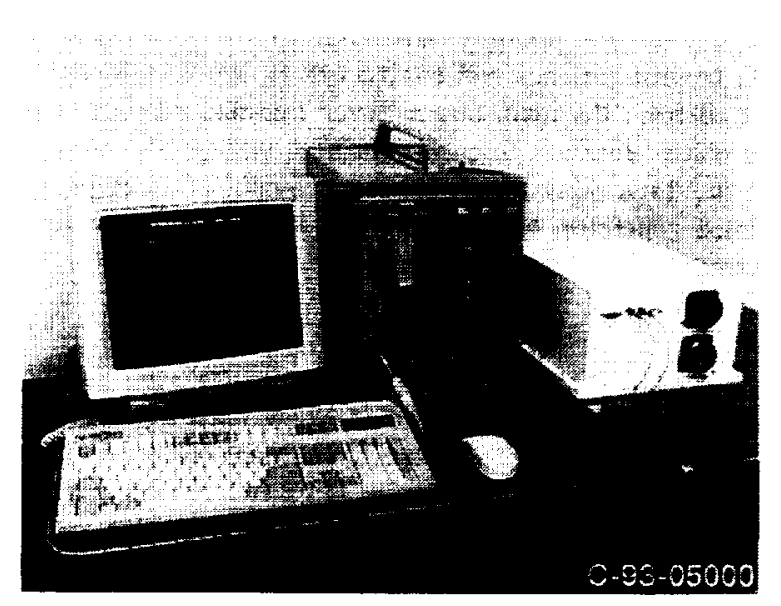

FIGURE 5: DC RESONANT LINK POWER PROCESSOR

Next, a $50 \mathrm{kw}$ DC resonant link motor drive was designed and demonstrated as reported in Schreiner, 1995 and Schreiner and Roth, 1992. Steady state motor testing demonstrated converter efficiencies of $96 \%$, and motor efficiencies approaching $86 \%$ at $27 \mathrm{Hp}$. EA subsystem tests on a dynamic test 
fixture demonstrated a force-speed capability of $7 \mathrm{in} / \mathrm{sec}$ at $32,000 \mathrm{lbf}$ load. On the inertial teststand, frequency response was measured as $5 \mathrm{~Hz}$ at $+1-0.1$ ". The low reactance of the induction motor was insufficient to integrate the motor current resulting in higher current ripple and a significant limitation in the torque output of the motor. Simulations of this system have shown that by including a filter network on the output of the converter, full power can be achieved. Other possible solutions include rewinding the motor to increase the leakage reactance, operating the converter at a higher switching frequency, or a combination. Program funding has not yet been available to test out any of these solutions.

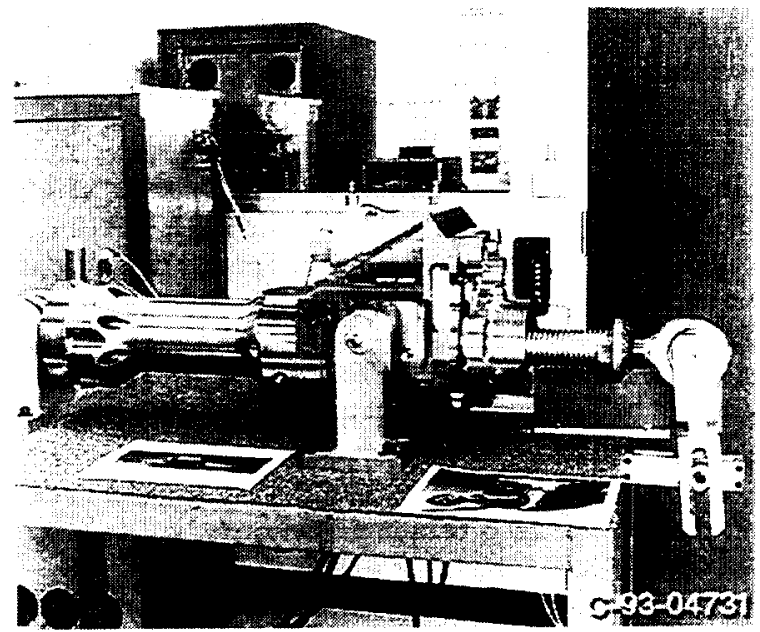

FIGURE 6: SSME/STME TVC ACTUATOR

\section{NASA ELV ELA System Modernization Program}

The Evolutionary Launch Vehicle Electric Actuation System Modemization Program is a multi-center NASA program involving JSC, KSC, MSFC and LeRC, as the lead center. The objective of the program is to demonstrate a redundant EA system, with upgraded power sources and advanced avionics. The target application is the TVC actuator subsystem for the Atlas booster. A successful end to end system demonstration will integrate redundancy management concepts with health management technology to enhance system reliability, maintainability and supportability resulting in substantial cost savings per launch.

MSFC is responsible for the power source development and component testing. JSC is responsible for the advanced avionics development. $\mathrm{KSC}$ is serving in an advisory role. The prime contractor is Lockheed Martin Astronautics Group. They are in partnership with NASA on this program and as such, are sharing the cost for this development. Other industry participants are LM Control Systems and GE CR\&D, responsible for the power electronics, and MPC Products, responsible for the motor and actuator development. LMAG is responsible for system requirements definition, system integra- tion and testing.

The actuator will be able to accomodate either two Permanent Magnet motors or two induction motors. Each of these components is in the design stage. The power electronics to drive the motors are an Auxiliary Resonant Commutated Pole Converter (ARCP) design. Control algorithms for the converter and the control algorithms for the motors reside in a Digital Signal Processor.

\begin{tabular}{|c|c|}
\hline \multicolumn{2}{|c|}{ Permanant Magnet motor specifications: } \\
\hline Rated Speed: & $18,000 \mathrm{rpm} @ 400 \mathrm{~Hz}$ \\
\hline Rated torque: & 700 in-ozs \\
\hline Peak Horsepower: & $12.5 \mathrm{Hp}$ \\
\hline Volume: & $3 " \times 5 "$ long \\
\hline Weight: & $7 \mathrm{lbs}$ \\
\hline \multicolumn{2}{|c|}{ Preliminary induction motor specifications: } \\
\hline Rated speed: & 24000 rpm@400Hz \\
\hline Rated torque: & 700 in-ozs \\
\hline Peak horsepower: & $16 \mathrm{Hp}$ \\
\hline Volume: & $3^{\prime \prime} \times 5 "$ long (includes resolver) \\
\hline Weight: & $7 \mathrm{lbs}$ \\
\hline
\end{tabular}

Actuator:

$\begin{array}{ll}\text { Rated load: } & 20,000 \mathrm{lbs} \\ \text { Stall force: } & 30,000 \mathrm{lbs} \\ \text { Rated speed: } & 3 \text { inches per second } \\ \text { Stroke: } & +1-2.8 \text { inches } \\ \text { Weight: } & 80 \mathrm{lbs} \\ \text { Length: } & 23.7^{\prime \prime}-29.3^{\prime \prime}\end{array}$

The program is on schedule and a system demonstration is planned for December of 1996. The actuator and both types of motors are to be delivered to Lockheed Martin in May 1996. The integrated system will be shipped to $L M A G$ in Denver for testing on their actuator test stand, with a facility DC power supply as the source. Redundancy management techniques and fault diagnostic methodologies will be demonstrated. At the present time, a decision has not yet been made on operation of the EA subsystem in the A-S or A-A mode for these tests. Both the Permanant Magnet motor driven EA and the Induction motor driven EA will be tested and evaluated. Both systems are torque-summed configurations.

An end-to-end system test will be conducted at the MSFC in December of 1996. The EA subsystem will be operated with a $\mathrm{AgZn}$ battery as the sole power source and with a $\mathrm{AgZn}$ battery/Super Capacitor combination as the source. The super capicitor will be developed by the University of Auburn and will be their Chemical Double Layer (CDL) design. Results of all the testing are to be released in the final report from the contractor early in 1997. 


\section{NASA Power by Wire EA's}

The NASA Power By Wire (PBW) program is a multi-year effort to design an all-electric secondary power system for a 300 passenger-class commercial aircraft. Studies conducted in the early 80 's and again in the early 90's have shown significant weight savings can be achieved by operating a single secondary power system - electric (Murray, 1992 and Hoffman, et al, 1985). Reduced aircraft weight results in lower fuel costs, increased range or cargo capacity. The main contractor for the PBW program is the McDonnell Douglas Aircraft Group. The subcontractor for the actuator portion of the contract is Honeywell. Honeywell will deliver one EMA and one EHA to McDonnell Douglas for testing on their system testbed. The EMA is a two channel, PM motor driven actuator. Each channel is rated at $25 \mathrm{HP}$. The EHA is dual tandom actuator with a rating of about $20 \mathrm{HP}$. Both will be delivered for testing in 1997. A flight actuator is also being developed by Parker Bertea for the program. This EHA will be flight tested in 1999 on NASA's 757 aircraft aileron surface. It will be powered off the existing three-phase $400 \mathrm{~Hz}$ power system.

\section{NASA Spoiler EA Development}

In addition to the main PBW contract effort, NASA is working with Boeing, under a Space Act Agreement, and with Lockheed Martin, under contract, to develop a redundant EA system for the Spoiler surface of the Boeing New Large Airplane. LM is responsible for the actuator and power electronics design and integration. Boeing has supplied the system requirements and will furnish the test site and equipment and will conduct the testing, with LM engineers. Allied Signal, subcontractor to LM, will develop the actuator and the IM.

The IM specifications:

$\begin{array}{ll}\text { Type: } & 3-\text { phase, } 4 \text { pole, squirrel cage motor } \\ \text { Peak Hp: } & 69 \mathrm{Hp} \\ \text { Max speed: } & 29,468 \mathrm{~mm} \\ \text { Efficiency: } & 90.2 \% @ \text { base rpm, 89\% @ peak rpm } \\ \text { Weight: } & 19.3 \mathrm{lbs} \\ \text { Volume: } & 4.25 " \times 9.0^{\prime \prime} \text { (includes resolver) }\end{array}$

The actuator specifications are as follows:

$\begin{array}{ll}\text { Type: } & \text { Ballscrew } \\ \text { Rated load: } & 36,000 \mathrm{lbf} \\ \text { Stall force: } & 44,700 \mathrm{lbf} \\ \text { No-load } & \\ \text { Slew rate: } & 7.2 \text { inches } / \mathrm{sec} \\ \text { Stroke: } & +1-1.5 \text { inches } \\ \text { Weight: } & 90 \mathrm{lbs} .\end{array}$

The Induction motor is currently under test at the LM facility in Binghamton, NY. The actuator delivery date is December 1996. EA system demonstration is tentatively scheduled for late 1997 or early 1998.

\section{CONCLUSION}

Various studies for both launch vehicles and aircraft have shown the potential benefits of EAs. Considerable progress has been made over the past five years on single string systems and individual components. Within the next two years, several redundant high power EA systems will be developed. These systems should demonstrate many of the benefits of electric actuation and establish the technology readiness of high power electric actuation systems for infusion into the next generation of launch vehicles and aircraft.

\section{REFERENCES}

Fulmer, C., 1993, "40 Hp Electromechanical Actuator Final Report", NAS3-25799.

Hall. D.K., and Merryman, S. A., 1995, "Hybrid Electrical Power Source for Thrust Vector Control ELectromechanical Actuation," IECEC Paper No. 95-26.

Hoffman, A. C., et al, 1985, "Advanced Secondary Power

System for Transport Aircraft," NASA Technical Paper 2463. McCleskey, C. M., and Rushing, H. W., 1992, "Electric

Actuators for Thrust Vector Control of Space Transportation Elements - Electric Actuation Analysis for Operational Consideration".

Murray, W. E., Feiner, L. J. and Flores, R. R., 1992, "Evaluation of All-Electric Secondary Power for Transport Aircraft", NASA CR-189077

Renz, D. D., 1992, "Comparison of All-Electric Secondary Power Systems for Civil Subsonic Transports,"

NASA TM 105852.

Schreiner, K. E., and Roth, M. E., 1992, "Resonant Mode Controllers for Launch Vehicle Applications,"

NASA TM 105563.

Schreiner, K. E., 1995, "Electromechanical Actuator Final Report - DC Resonant Link System," NAS3-25799. 

Public reporting burden for this collection of Intormation is estimated to average 1 hour per response, Including the tima for reviewing Instructions, searching existing data sources, gethering and maintalning the data needed, and completing and reviewing the collection of intormation. Send comments regarding this burden extimate or any other aspect of this collection of information. Including suggestions for reducing this burden, to Washington Headquarters Services. Oirectorate lor Iniormation Operations and Aeponts, 1215 Jellon

\begin{tabular}{|l|l|l}
\hline 1. AGENCY USE ONLY (Leave blank) & $\begin{array}{c}\text { 2 REPORT DATE } \\
\text { September } 1996\end{array}$ & $\begin{array}{r}\text { 3. REPOAT TYPE AND DATES COVERED } \\
\text { Technical Memorandum }\end{array}$
\end{tabular}

4. TITL AND SUBTIILE

Status of Electrical Actuator Applications

6. AUTHOR(S)

Mary Ellen Roth, Linda M. Taylor, and Irving G. Hansen
5. FUNDING NUMBERS

WU-538-01-11
8. PEAForIm ORGANIZATION REPORT NUMBER

E-10416

National Aeronautics and Space Administration

Lewis Research Center

Cleveland, Ohio 44135-3191

10. SPONSORINGMONITORING AGENCY REPORT NUMBER

National Aeronautics and Space Administration

Washington, D.C. 20546-0001

NASA TM-107319

11. SUPPLEMENTARY NOTES

Prepared for the 31 st Intersociety Energy Conversion Engineering Conference cosponsored by IEEE, AIChE, ANS, SAE, AIAA, and ASME, Washington D.C., August 11-16, 1996. Mary Ellen Roth and Linda M. Taylor, NASA Lewis Research Center, Irving G. Hansen, Motive Power Development, 7905 Silverton Ave., Suite 109, San Diego, California 92126 (work funded under NASA Contract NAS3-27015). Responsible person, Mary Ellen Roth, organization code 5430, (216) 433-8061.

12a. DISTRIBUTIONAVALLABIUTY STATEMENT 12b. DISTRIBUTION CODE

Unclassified - Unlimited

Subject Categories 01, 15, and 33

This publication is available from the NASA Center for AeroSpace Information, (301) 621-0390

13. ABSTRACT (Maximum 200 words)

An ever increasing number of actuation functions historically performed by hydraulics or pneumatics are being accomplished by electric actuation. If "end to end" systems are considered, electric actuators (EA's) are potentially lighter and more efficient. In general, system redundancies may be more easily implemented and operationally monitored. Typically, electrical components exhibit longer mean times to failure and projected lifetime costs of EA's are potentially much lower than those of other options. EA's have certain characteristics which must be considered in their application. The actual mechanical loadings must be established, for the more easily controlled EA may be operated much closer to its full capabilities. At higher rates of motion, EA's are operating as constant power devices. Therefore, it may be possible to start a movement that can not be stopped. The incorporation of high power electronics into remote locations introduces new concerns of EMI and thermal control. It is the management of these and other characteristics that forms the engineering design challenges. Work is currently in progress on EA's for aircraft and expendable launch vehicles. These applications span from ten to $40+$ horsepower. The systematics and status of these actuators will be reported along with current technical trends in this area.

\section{SUBJECT TERMS}

Electrical actuation; Launch vehicles; Aircraft; Resonant power processor, Induction motor; PM motor

17. SECURTY CLASSIFICATION
OF REPORT
Unclassified

NSN 7540-01-280-5500
18. SECURTY CLASSIFICATION OF THIS PAGE Unclassified
19. SECURITY CLASSIFICATION OF ABSTRACT Unclassified
15. NUMBER OF PAGES 8

16. PAICE CODE $\mathrm{A02}$

20. LIMTATTON OF ABSTRACT

Standard Form 298 (Rev. 2-89) Prescribed by ANSI SId. Z39-18 298-102 